Counting and Counters 
By the same author

Digital Circuits for Binary Arithmetic 


\section{Counting and Counters}

R. M. M. Oberman

Professor in Information Engineering

Technical University

Delft, The Netherlands 
(C) R. M. M. Oberman 1981

Softcover reprint of the hardcover 1st edition 1981 978-0-333-30512-6

All rights reserved. No part of this publication may be reproduced or transmitted, in any form or by any means, without permission.

First published 1981 by

THE MACMILLAN PRESS LTD

London and Basingstoke

Associated companies in Delhi Dublin

Hong Kong Johannesburg Lagos Melbourne

New York Singapore and Tokyo

Typeset in 10/12 Press Roman by

STYLESET LIMITED

Salisbury · Wiltshire

ISBN 978-1-349-81365-0

ISBN 978-1-349-81363-6 (eBook)

DOI 10.1007/978-1-349-81363-6

This book is sold subject to the standard conditions of the Net Book Agreement. 
Counting starts with zero and not with one 


\section{Contents}

Preface $\quad$ xi

1. Counting with Numbers 1

$\begin{array}{ll}1.0 \text { Number Systems } & 1\end{array}$

1.1 Polynomial Number Representation 2

Factorial representation $\quad 2$

Combinatorial representation $\quad 3$

Modular representation $\quad 5$

1.2 Some Extensions of the Polynomial Representation 6

$\begin{array}{ll}\text { The signed-digit number system } & 6\end{array}$

$\begin{array}{ll}\text { The reflected binary number system } & 8\end{array}$

1.3 Weight Concepts $\quad 8$

$\begin{array}{ll}1.4 \text { Number Systems with Error-detecting Power } & 10\end{array}$

$\begin{array}{ll}1.5 \text { Number Systems with Error-correcting Power } & 11\end{array}$

$\begin{array}{ll}1.6 \text { Counting Algorisms } & 13\end{array}$

$\begin{array}{lr}1.7 \text { High-speed Counting } & 15\end{array}$

$\begin{array}{ll}\text { References } & 16\end{array}$

2. Binary Counters 17

$\begin{array}{ll}2.0 \text { Introduction } & 17\end{array}$

2.1 Binary Counters using T Flip-flops as Switching Elements 20

2.2 Circuit Design via Karnaugh Maps 23

2.3 The Features of the Counter 25

The flip-flop type $\quad 25$

Load and clear functions $\quad 26$

The carry problem $\quad 28$

2.4 Special Forms of Binary Counter 29

Binary-decimal counters $\quad 29$

Up-down counters $\quad 34$

2.5 Counters with Error-detecting and Error-correcting Power 36

Binary counters with single error-detection $\quad 36$

Binary counters with single error-correction $\quad 38$ 
2.6 The Binary Rate Multiplier $\quad 41$

2.7 Some Variations on Binary Counters 43

Binary counter with variable starting section $\quad 43$

Divide-by- $N$ counters $\quad 44$

$\begin{array}{ll}\text { Negabinary counter } & 47\end{array}$

2.8 Interference-resistant Binary Counter $\quad 47$

2.9 High-speed Counting $\quad 49$

References $\quad 50$

3. Reflected Binary Counters 51

3.0 Introduction 51

3.1 The Design of a 4-bit Synchronous Reflected Binary Counter 54

3.2 The Design of a Combined Reflected Binary, Signed-digit and 60 Natural Binary Counter

3.3 The Design of a Reflected Binary Decimal Counter 61

Decimal up-down counter $\quad 63$

3.4 Single Error-correcting Reflected Binary Counter 63

The detection of the number of the erroneous bit 66

$\begin{array}{ll}\text { The error-correction } & 67\end{array}$

$\begin{array}{lr}\text { References } & 69\end{array}$

4. Constant-ratio Counters 70

$\begin{array}{ll}4.0 \text { Introduction } & 71\end{array}$

4.1 Constant-ratio Codes with the Words in Non-lexicographic Order 71

$\begin{array}{ll}\text { Characterisation of essential code words } & 75\end{array}$

4.2 The Generation of a Complete Cycle of Code Words 78

$\begin{array}{ll}\text { The jump detection } & 78\end{array}$

4.3 The Design of Jumping Diagrams for Codes with $M=4 \quad 83$

4.4 Constant-ratio Codes with a Word Sequence in Lexicographic Order $\quad 87$

4.5 Constant-ratio Code Counters, Lexicographic Order 89

Counter consisting of $N \mathrm{~J}$-K flip-flops $\quad 92$

4.6 Constant-ratio Bar Codes 96

References $\quad 99$

5. Accumulative Counters 100

$\begin{array}{ll}5.0 \text { Introduction } & 100\end{array}$

$\begin{array}{ll}5.1 \text { Decimal Counters } & 101\end{array}$

5.2 The Rate Multiplier-Accumulator $\quad 106$

$\begin{array}{ll}\text { Arbitrary rate multiplier, fixed rate } & 109\end{array}$

Programmable arbitrary rate multiplier $\quad 110$

$\begin{array}{ll}\text { References } & 111\end{array}$

6. Shift Register Counters $\quad 112$

\begin{tabular}{ll}
6.0 Introduction ' & 112 \\
\hline
\end{tabular}

$\begin{array}{lll}\text { 6.1 Linear Counters } & 112\end{array}$

Interference-resistant linear counter $\quad 114$ 
6.2 Transmitters and Receivers of Binary Information 115 $\begin{array}{ll}\text { The transmitter } & 116\end{array}$

$\begin{array}{ll}\text { 6.3 The Linear Counter with a Number of } 1 \text { Bits } & 117\end{array}$

6.4 Shift Register Counters with Inverted Feedback 118

$\begin{array}{ll}6.5 \text { Shift Registers as Prescalers } & 121\end{array}$

$\begin{array}{ll}\text { References } & 124\end{array}$

7. Pseudo-random Sequence Generators 125

$\begin{array}{ll}7.0 \text { Introduction } & 125\end{array}$

$\begin{array}{ll}\text { 7.1 The } m \text { Sequence Generator } & 127\end{array}$

7.2 Composite Pseudo-random Sequence Generator 133

$\begin{array}{ll}\text { Calculation of the number of wheel revolutions } & 136\end{array}$

The wheels

7.3 Pseudo-random Decimal Number Generator $\quad 141$

$\begin{array}{ll}\text { References } & 143\end{array}$

8. Function Counters 145

$\begin{array}{ll}8.0 \text { Introduction } & 145\end{array}$

$\begin{array}{ll}8.1 N_{\alpha}{ }^{n} \text { Counters } & 145\end{array}$

$8.2 \sqrt[m]{N_{\alpha} \text { Counters }} \quad 149$

$8.3 \log _{2} N_{\alpha}$ Counter $\quad 153$

$\begin{array}{ll}8.41 / N_{\alpha} \text { Counter } & 155\end{array}$

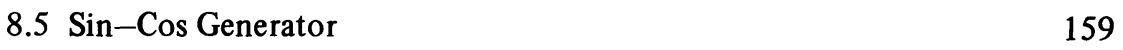

Increment-difference $\sin \alpha$ counter $\quad 161$

$\begin{array}{ll}\text { 8.6 The Fibonacci Sequence Generator } & 162\end{array}$

$\begin{array}{ll}\text { Reference } & 164\end{array}$

9. Gateless Synchronous Counters with J-K Flip-flops 165

$\begin{array}{ll}9.0 \text { Introduction } & 165\end{array}$

9.1 Gateless Counters with J-K Flip-flops having Multiple Inputs 167

9.2 Gateless Counting Shift Registers with J-K Flip-flops 168

$\begin{array}{lr}\text { References } & 169\end{array}$

$\begin{array}{lr}\text { Index } & 170\end{array}$ 


\section{Preface}

During the forty years in which the design of switching circuits has been increasingly developed as a science, the design of counters has, in my experience, always been an excellent proving ground for anyone who has mastered Boolean algebra for the design of gate circuits and has acquired some knowledge of the design of sequential circuits that perform shifting and counting operations.

Counters are sequential circuits with a well-defined basic operation. They can be designed through an operating algorism or a system description; equally, they can be designed using operating tables and Karnaugh maps, from which the final switching equations are derived.

Both methods are demonstrated in the text. However, the design method using algorisms or system concepts has been given preference because in the author's opinion this method provides the designer with the best insight into what he is really doing.

This book is intended to be used at the graduate level of study in digital electronics. Counting has always been and will always be an important operation in any automated technical system or organisation. It is therefore an important tool for the education of students in the science of digital techniques. A knowledge of counters is not only important in itself, it is even more important from the point of view of the insight it provides into the solution of switching problems.

A number of the counter designs discussed in the text have been used as student projects which could be carried out instead of a formal examination. The results of this type of student assessment have been extremely good.

The foregoing remarks about the scope of this book might give the impression that it is intended for teaching purposes only, but this is not so. The book contains more material than should be taught in a single course. Many different types of counting problem, a number of which are published for the first time, have been treated; thus the text will also be useful for many people working on the design of switching circuits. They will need this book as a reference and an explanation of the operation of commercially available counter circuits in integrated form. There are many different types of counter since counting is a part of almost every type of switching circuit. 
In this book the concept of counting is treated very broadly. The author considers any circuit running through a cycle of states to be a counter. Its output may have a clear and well-defined relationship with the number of input pulses, but this relationship can also have a pseudo-random character, equally well-defined, but very difficult to state in the form of mathematical equations.

The author wishes to thank his colleagues A. J. van de Goor and A. Snijders for their careful reading of the manuscript and his laboratory staff for testing many of the counter circuits included in the text.

R. M. M. OBERMAN 